\title{
Characterization of Verticillium albo-atrum Field Isolates Using Pathogenicity Data and AFLP Analysis
}

Sebastjan Radišek, Plant Protection Department, Institute of Hop Research and Brewing Žalec, Cesta Žalskega tabora 2, 3310 Žalec, Slovenia; Jernej Jakše, Centre for Plant Biotechnology and Breeding, Biotechnical Faculty, Jamnikarjeva 101, 1000 Ljubljana, Slovenia; Andrej Simončič, Plant Protection Department, Institute of Hop Research and Brewing Žalec; and Branka Javornik, Centre for Plant Biotechnology and Breeding, Biotechnical Faculty

\section{ABSTRACT}

Radišek, S., Jakše, J., Simončič, A., and Javornik, B. 2003. Characterization of Verticillium albo-atrum field isolates using pathogenicity data and AFLP analysis. Plant Dis. 87:633-638.

Since 1997, hop wilt induced by a virulent pathotype of Verticillium albo-atrum has caused considerable economic losses in hop fields in Slovenia. In all, 20 isolates of V. albo-atrum, including 12 from plants affected with the lethal form (PG2) of hop wilt, 6 from plants with the mild form (PG1), 1 from cucumber, and 1 from petunia, as well as 1 isolate of $V$. dahliae each from hop and green pepper, were analyzed by amplified fragment length polymorphism (AFLP). Differences in the virulence of hop isolates were confirmed by pathogenicity tests on hop cultivars. The AFLP method was optimized for analysis of these fungi and 7 of 39 primer combinations tested were used for the analysis of polymorphism among isolates. Cluster analysis of AFLP data divided the isolates into two, well-separated $V$. albo-atrum and V. dahliae clusters, confirming that the two species are genetically distinct. Within the V. albo-atrum cluster, isolates were further separated into two distinct groups: the A1 group contained PG1 hop pathotype and cucumber and petunia isolates, and the A2 group all hop isolates of the PG2 pathotype. Minor genetic variation was detected within pathotype-associated AFLP groups, but the clear separation of $V$. albo-atrum hop isolates according to their level of virulence shows genetic differentiation among hop V. albo-atrum pathotypes.

Hop wilt, caused by Verticillium alboatrum Reinke \& Berthold or $V$. dahliae Kleb., is one of the most important diseases of hop. This soilborne fungus enters the hop by root invasion and then colonizes the hop vascular system. Once a hop field is contaminated, planting resistant cultivars and carrying out phytosanitary measures are the only effective means of control against this disease. Hop wilt was first reported in England (10) and V. alboatrum was considered the infectious agent. Keyworth (14) later identified two different forms of hop wilt, fluctuating (mild) and progressive (lethal) wilt. The difference between the forms is that the lethal form causes withering of hop; whereas in the mild form, plants, although infected, continue to grow. Isolates causing progressive wilt have been further divided into three different strains by the level of pathogenicity to hop cultivars $(4,29)$.

Corresponding author: B. Javornik E-mail: branka.javornik@uni-lj.si

This study was funded by the Ministry of Education, Science and Sport, contract no. S4-486019/20162 and PO-0513-0481.

Accepted for publication 20 December 2002.

Publication no. D-2003-0331-03R

(C) 2003 The American Phytopathological Society
Hop wilt was first discovered in Slovenia in 1974, in the mild form, as the result of infections by $V$. albo-atrum and V. dahliae (5). Until 1997, the disease appeared only sporadically in some hop fields; however, in that year, an outbreak of the lethal form of hop wilt was registered in the western part of the Savinja valley. During the next 3 years, the lethal form of the disease caused by $V$. albo-atrum spread rapidly through the western part of the Savinja valley and, to date, has affected more than 90 ha of hop fields (25). The disease is currently a serious threat to the main hop production areas in Slovenia. Hop wilt studies have established that the difference between mild and lethal outbreaks was due to differences in the virulence of the pathogen (12). It is also known that disease severity is strongly influenced by the susceptibility of hop cultivars and environmental conditions, such as low soil temperatures and nitrogen fertilizer applications $(28,30)$. The characterization of the pathogen population according to variation in virulence is important for disease management strategies, and hop isolates of $V$. albo-atrum have been best characterized thus far by pathogenicity tests on hop cultivars $(4,29)$. Molecular techniques as alternative and rapid methods for the characterization of $V$. albo-atrum isolates have also been employed; in particular, restriction fragment length polymorphism (RFLP; 1,9,31), sequencing of the internal transcribed spacer (ITS) of nuclear rDNA $(3,18,19)$, and random amplified polymorphic DNA (RAPD; 15,22). These studies have demonstrated the genetic variation among various $V$. albo-atrum isolates and, thus far, have enabled the division of isolates into two clear host-adapted groups, L (lucerne) and NL (all other hosts). Hop isolates causing mild or lethal wilt have also been placed in the NL group without differentiation with regard to their pathogenicity (11).

The appearance of hop wilt in the Slovene hop-growing region required characterization of field isolates. Pathogenicity tests on hop cultivars and molecular characterization of isolates using amplified fragment length polymorphism (AFLP) analysis were employed for this purpose. In this study, we report on the use of the AFLP method compared with pathogenicity tests for differentiation between mild and lethal pathotypes of $V$. albo-atrum field hop isolates from Slovenia.

\section{MATERIALS AND METHODS}

Fungal isolates. In all, 18 field isolates of $V$. albo-atrum from hop, 1 from cucumber, and 1 from petunia; and 2 isolates of $V$. dahliae, 1 from hop and 1 from green pepper, were analyzed (Table 1). Twelve isolates of $V$. albo-atrum were isolated from infected hop plants with the lethal form of hop wilt and six isolates from plants with the mild form of hop wilt. The hop isolates originated from different infected cultivars from the main hop-growing areas in Slovenia and were collected in the years 1998 to 2000. The remaining isolates also were collected in Slovenia during the same period. All isolates were maintained in the culture collection of the Institute of Hop Research and Brewing Žalec, Slovenia; as monosporic cultures on potato dextrose agar (PDA) at $4^{\circ} \mathrm{C}$ in the dark. The species identity of each isolate was checked by light microscopy.

Pathogenicity tests. Eight isolates of $V$. albo-atrum isolated from plants with the lethal form of hop wilt and four from the mild form were assessed by pathogenicity test. Hop cultivars that were susceptible (Fuggle and Celeia), moderately resistant (Cicero), and resistant (Wye Target) to infection by $V$. albo-atrum were used as reference cultivars $(4,25,29)$. The plant material was obtained from the hop germ 
Table 1. Analysis of Verticillium isolates and their grouping as determined by pathogenicity test and amplified fragment length polymorphism (AFLP) analysis

\begin{tabular}{|c|c|c|c|c|c|}
\hline Species, lane ${ }^{x}$ & $\begin{array}{c}\text { Isolate } \\
\text { designation }\end{array}$ & Host & $\begin{array}{c}\text { Year of } \\
\text { isolation }\end{array}$ & $\begin{array}{c}\text { Pathogenicity } \\
\text { group }^{y}\end{array}$ & $\begin{array}{c}\text { AFLP } \\
\text { analysis }^{z}\end{array}$ \\
\hline \multicolumn{6}{|l|}{ V. albo-atrum } \\
\hline 1 & Or00 & Hop & 2000 & PG2 & $\mathrm{A} 2$ \\
\hline 2 & Prev & Hop & 1998 & PG2 & A2 \\
\hline 3 & Or99 & Hop & 1999 & $\ldots$ & $\mathrm{A} 2$ \\
\hline 4 & Pust & Hop & 2000 & PG2 & $\mathrm{A} 2$ \\
\hline 5 & Vran & Hop & 2000 & PG2 & A2 \\
\hline 6 & $\mathrm{Laz}$ & Hop & 2000 & $\ldots$ & $\mathrm{A} 2$ \\
\hline 7 & $\operatorname{Tr} 98$ & Hop & 1998 & $\ldots$ & A2 \\
\hline 8 & Roz & Hop & 2000 & PG2 & A2 \\
\hline 9 & $\mathrm{Ciz}$ & Hop & 2000 & PG2 & $\mathrm{A} 2$ \\
\hline 10 & Ranc & Hop & 1998 & PG2 & A2 \\
\hline 11 & Pov & Hop & 1999 & $\ldots$ & $\mathrm{A} 2$ \\
\hline 12 & Tr99 & Hop & 1999 & PG2 & $\mathrm{A} 2$ \\
\hline 13 & Ocer & Hop & 1998 & PG1 & A1 \\
\hline 14 & Kres99 & Hop & 1999 & PG1 & A1 \\
\hline 15 & CasA & Hop & 2000 & $\ldots$ & A1 \\
\hline 16 & Zup & Hop & 1999 & PG1 & A1 \\
\hline 17 & $\operatorname{Rec}$ & Hop & 1999 & PG1 & A1 \\
\hline 18 & Mo3 & Hop & 1999 & $\ldots$ & A1 \\
\hline 19 & Surf & Petunia & 2000 & $\ldots$ & A1 \\
\hline 20 & Kum & Cucumber & 1999 & $\ldots$ & A1 \\
\hline \multicolumn{6}{|l|}{ V. dahliae } \\
\hline 21 & CasD & Hop & 1999 & $\ldots$ & \\
\hline 22 & Pap & Green pepper & 1999 & $\ldots$ & \\
\hline
\end{tabular}

$x$ Refers to lane in Figure 1.

y PG2, isolates causing lethal form of hop wilt; PG1, isolates causing mild form of hop wilt; ..., not tested.

z A2, AFLP group 2; A1, AFLP group 1.

Table 2. Results of pathogenicity tests on four hop cultivars with Verticillium albo-atrum isolates ${ }^{\mathrm{x}}$

\begin{tabular}{lcccccc}
\hline & \multicolumn{3}{c}{ Cultivar } & \\
\cline { 2 - 5 } Isolate & Wye Target & Fuggle & Celeia & Cicero & Mean & Group $^{\mathbf{z}}$ \\
\hline Or00 & 0 & 50.9 & 62.7 & 4.1 & $29.4 \mathrm{a}$ & PG2 \\
Prev & 0.5 & 54.3 & 59.6 & 3.5 & $29.5 \mathrm{a}$ & PG2 \\
Pust & 0.3 & 52.3 & 57.3 & 1.4 & $27.8 \mathrm{a}$ & PG2 \\
Vran & 0.2 & 46.7 & 52.8 & 1.1 & $25.2 \mathrm{a}$ & PG2 \\
Roz & 0.5 & 54.8 & 57.0 & 4.0 & $29.1 \mathrm{a}$ & PG2 \\
Ciz & 0.4 & 49.9 & 58.4 & 3.1 & $28.0 \mathrm{a}$ & PG2 \\
Ranc & 0.9 & 54.6 & 59.3 & 2.9 & $29.4 \mathrm{a}$ & PG2 \\
Tr99 & 0.9 & 48.6 & 55.6 & 3.4 & $27.1 \mathrm{a}$ & PG2 \\
Ocer & 0 & 3.8 & 4.7 & 0 & $2.1 \mathrm{~b}$ & PG1 \\
Kres99 & 0 & 4.5 & 5.1 & 0 & $2.4 \mathrm{~b}$ & PG1 \\
Zup & 0 & 3.5 & 4.2 & 0 & $1.9 \mathrm{~b}$ & PG1 \\
Rec & 0 & 3.9 & 4.8 & 0 & $2.2 \mathrm{~b}$ & PG1 \\
\hline
\end{tabular}

${ }^{\mathrm{x}}$ Data refers to the mean severity index for 10 replicated plants for each isolate-cultivar combination 42 days after inoculation.

y Means with the same letter do not differ significantly at the 5\% level (Duncan's multiple range test).

${ }^{\mathrm{z}}$ Pathogenicity groups: PG2, isolates causing lethal form of hop wilt; PG1, isolates causing mild form of hop wilt.

Table 3. Primer combinations of EcoRI and $M s p I$ used in the amplified fragment length polymorphism (AFLP) analysis of 22 isolates of Verticillium albo-atrum and V. dahliae and detected polymorphism

\begin{tabular}{|c|c|c|c|c|}
\hline Primer combination & $\begin{array}{c}\text { V. albo-atrum/ } \\
\text { V. dahliaew }\end{array}$ & V. albo-atrum ${ }^{\mathrm{x}}$ & $\begin{array}{l}\text { V. albo-atrum } \\
(\mathrm{L} / \mathrm{M})^{\mathrm{y}}\end{array}$ & V. dahliae ${ }^{\mathrm{z}}$ \\
\hline EcoRI-AC/MspI-GT & 35 & 2 & 1 & 1 \\
\hline EcoRI-AC/MspI-TA & 31 & 2 & 2 & 0 \\
\hline EcoRI-AC/MspI-TC & 30 & 2 & 2 & 0 \\
\hline EcoRI-GA/MspI-AT & 27 & 2 & 2 & 0 \\
\hline EcoRI-GA/MspI-TA & 29 & 2 & 2 & 1 \\
\hline EcoRI-GT/MspI-GA & 36 & 3 & 2 & 2 \\
\hline EcoRI-TC/MspI-TA & 30 & 2 & 2 & 1 \\
\hline
\end{tabular}

${ }^{\mathrm{w}}$ Number of polymorphic bands between V. albo-atrum and V. dahliae isolates.

${ }^{x}$ Number of polymorphic bands among V. albo-atrum isolates.

y Number of polymorphic bands between lethal (L) and mild (M) V. albo-atrum hop isolates.

${ }^{\mathrm{z}}$ Number of polymorphic bands between $V$. dahliae isolates. plasm collection of the Institute of Hop Research and Brewing Žalec, Slovenia, as clonally propagated cuttings. The plants were grown in 4-liter plastic pots containing a mixture of $50 \%$ peat, $35 \%$ clay, $15 \%$ humus, and a slow-release fertilizer (Scotts Osmocote, $14 \mathrm{~N}-14 \mathrm{P}-14 \mathrm{~K}$, at $4 \mathrm{~kg} / \mathrm{m}^{3}$ ). Plant growth was restricted to a single bine with regular pruning of the lateral shoots. Pathogenicity tests were performed in an isolated test plot under field environmental conditions. Ten plants of each hop cultivar were inoculated by a single isolate. Inoculum was prepared by growing monosporic cultures of the isolates on PDA plates at room temperature for 10 days in the dark. The cultures were rinsed with sterile distilled water and the conidial density of the isolates was adjusted with a Thoma counting chamber (Brand $\mathrm{GMBH}+\mathrm{CO} \mathrm{KG}$, Wertheim, Germany) to approximately $2 \times$ $10^{6}$ conidia/ml. Six-week-old plants were inoculated by stem-puncture inoculation in the basal part of the bine. Control plants were similarly injected with sterile distilled water. After inoculation, single strings, suspended from overhead wirework (3 m high), were attached to each pot. Symptoms were assessed 4 weeks after inoculation and then at weekly intervals for a further 2 weeks on a 0 -to- 5 scale according to the proportion of foliage affected by wilt symptoms, where $0=$ no leaf symptoms, 1 $=1$ to $20 \%$ leaf area wilted, $2=21$ to $40 \%$ leaf area wilted, $3=41$ to $60 \%$ leaf area wilted, $4=61$ to $8 \%$ leaf area wilted, and $5=81$ to $100 \%$ leaf area wilted. The level of disease severity for each plant was expressed by a severity index which was calculated according to the Townsend-Heuberger formula (24). The severity indexes were subjected to one-way analysis of variance, and significant mean differences $(P=0.05)$ were determined with Duncan's multiple range test.

DNA extraction. Isolates were grown by agitation on a rotary shaker $(50 \mathrm{rpm})$ in $50 \mathrm{ml}$ of general fungal medium (32) at room temperature for 4 to 5 days in the dark. Mycelia were harvested by centrifugation at $2,500 \times g$ for $5 \mathrm{~min}$ and rinsed with sterile distillate water. DNA of the isolates was extracted by the method of Lee and Taylor (16) with some modifications. Mycelia of isolates were frozen in liquid nitrogen and ground to a fine powder. Extraction buffer $(50 \mathrm{mM}$ Tris- $\mathrm{HCl}$, $\mathrm{pH}$ 7.2, $50 \mathrm{mM}$ EDTA, 3\% sodium dodecyl sulfate, and $1 \% \quad \beta$-mercaptoethanol) was added and the mixture was incubated at $68^{\circ} \mathrm{C}$ for $1.5 \mathrm{~h}$. Samples were extracted three times with equal volumes of phenol:chloroform:isoamyl alcohol (25:24:1) and centrifuged at $15,000 \times g$ for $15 \mathrm{~min}$. DNA from the supernatant was precipitated with $1 / 10$ volume of $3 \mathrm{M} \mathrm{Na-acetate,} \mathrm{pH}$ 5.2, and 1 volume of isopropanol. The resuspendent pellet was treated with $8 \mu \mathrm{l}$ of RNAse (10 mg/ml; Sigma-Aldrich, St. Louis) at $37^{\circ} \mathrm{C}$ for an hour and re-extracted 
with phenol:chloroform:isoamyl alcohol (25:24:1). The DNA was precipitated, washed in 70\% ethanol, and resuspended in TE buffer (10 mM Tris-HCl, $\mathrm{pH} 8.0$, and $1 \mathrm{mM}$ EDTA, $\mathrm{pH}$ 8.0). The quality of the DNA was determined by agarose gel electrophoresis and quantified by fluorimetry.

AFLP analysis. The AFLP protocol was optimized for the analysis of $V$. albo-atrum and $V$. dahliae (26). Genomic DNA (500 ng) was digested overnight at $37^{\circ} \mathrm{C}$ with $2.5 \mathrm{U}$ each of EcoRI and MspI restriction enzymes. Digestion was checked on $1 \%$ agarose gels. After digestion, the restriction fragments were ligated with adapters by adding $10 \mu$ l of ligation mixture ( $5 \mathrm{pmol}$ EcoRI adapter, 50 pmol MspI adapter, 1× T4 DNA Ligase buffer $[50 \mathrm{mM}$ Tris- $\mathrm{HCl}$, $10 \mathrm{mM} \mathrm{MgCl} 2,10 \mathrm{mM}$ ditiotreitol, $1 \mathrm{mM}$ ATP, bovine serum albumin at $25 \mu \mathrm{g} / \mu \mathrm{l}, \mathrm{pH}$ 7.8], 1 Weiss U of T4 Ligase (New England Biolabs $\mathrm{GmbH}$, Frankfurt, Germany) to the restriction mixture, and incubated for $3 \mathrm{~h}$ at $37^{\circ} \mathrm{C}$. The adapter-ligated fragments served as templates for primers in polymerase chain reaction (PCR).

Preamplifications were performed with EcoRI (5' GACTGCGTACCAATTC 3') and $M s p I$ ( $5^{\prime}$ GATGAGTCCTGAGCGG $\left.3^{\prime}\right)$ primers having no selective nucleotides. The reaction mixture was as follows: $50 \mathrm{ng}$ of DNA, $75 \mathrm{ng}$ of each primers, $1.25 \mathrm{U}$ of Taq polymerase (Promega Corp., Madison, WI), 10× PCR buffer (10 mM Tris- $\mathrm{HCl}$, $\left.1.5 \mathrm{mM} \mathrm{MgCl}_{2}, 50 \mathrm{mM} \mathrm{KCl}, \mathrm{pH} 8.3\right)$, and $0.2 \mathrm{mM}$ dNTP. Reactions were performed in a PCR System 9700 (Perkin-Elmer Corp., Norwalk, CT), programmed for 20 cycles with the following temperature profile: $30 \mathrm{~s}$ at $94^{\circ} \mathrm{C}, 60 \mathrm{~s}$ at $56^{\circ} \mathrm{C}$, and $60 \mathrm{~s}$ at $72^{\circ} \mathrm{C}$. In the second amplification for the initial screening, 4 EcoRI and $10 \mathrm{MspI}$ primers with two selective nucleotides were used. The reaction mixture contained $15 \mathrm{ng}$ of each primer, $2 \mu \mathrm{l}$ of preamplified DNA, 10× PCR buffer, 0.3 U of Taq polymerase, and $0.2 \mathrm{mM}$ dNTP. The following temperature profile was used: 13 cycles of $30 \mathrm{~s}$ at $94^{\circ} \mathrm{C}, 60 \mathrm{~s}$ at $65^{\circ} \mathrm{C}$, and $60 \mathrm{~s}$ at $72^{\circ} \mathrm{C}$, in which the annealing temperature was subsequently reduced by $0.7^{\circ} \mathrm{C}$ each cycle. Selective amplification was continued with 23 cycles of $30 \mathrm{~s}$ at $94^{\circ} \mathrm{C}, 60 \mathrm{~s}$ at $56^{\circ} \mathrm{C}$, and $60 \mathrm{~s}$ at $72^{\circ} \mathrm{C}$. The PCR products were separated on $5 \%$ denaturing polyacrylamide gels, containing $1 \times$ TBE buffer (90 mM Tris-borate, 2 mM EDTA, $\mathrm{pH}$ 8.9) and $8 \mathrm{M}$ urea. Bands were visualized with silver staining using the Promega Silver Sequence protocol, with some modifications $(7,13)$.

Data analysis. All gels were scored visually for both polymorphic and monomorphic bands. Each band was treated as a unit character and scored for presence and absence, including only reproducible bands from repeated AFLP analysis. The Jaccard (J) coefficient of similarity was used to generate a similarity matrix, from which a dendrogram was constructed via the un- weighted paired group method, using arithmetic means (UPGMA). All calculations were performed using the computer software package NTSYS 2.02-pc (27).

\section{RESULTS}

Pathogenicity test. Pathogenicity data for the 12 tested $V$. albo-atrum isolates were determined by artificial inoculations of hop cultivars Fuggle, Wye Target, Celeia, and Cicero. The cultivars expressed symptoms 4 weeks after the inoculation as intervenial chlorosis, necrosis, and defoliation of plants. Measurements of disease severity for each of the four hop cultivars revealed differences in the pathogenicity.

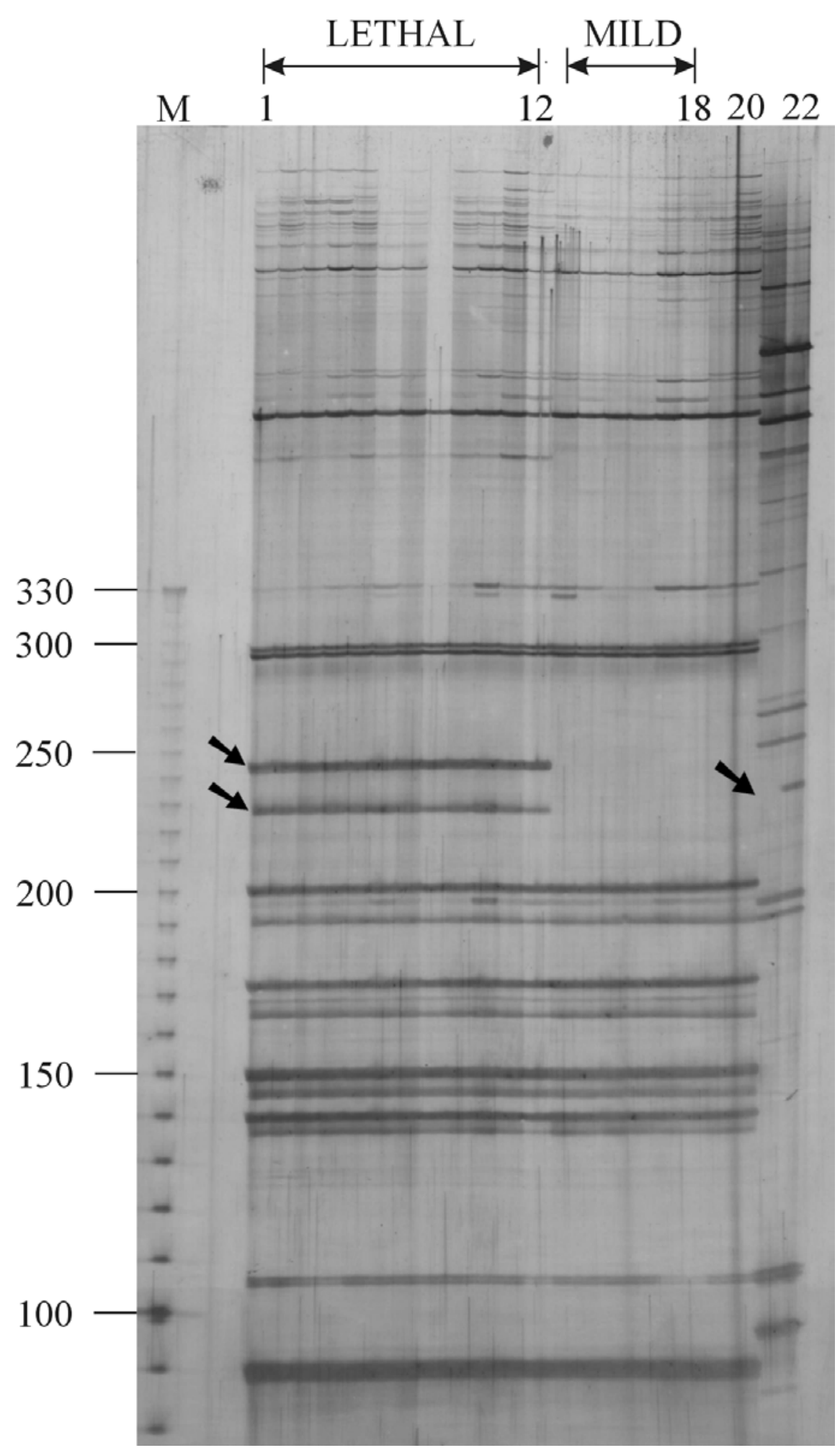

Fig. 1. Amplified fragment length polymorphism (AFLP) patterns of Verticillium albo-atrum and $V$. dahliae isolates using the EcoRI-TC/MspI-TA primer combination. Lanes 1 to 18 represent the $V$. albo-atrum hop isolates as designated in Table 1. Lanes 21 and 22 are isolates of $V$. dahliae from hop and green pepper. M, size markers. Arrows indicate polymorphic AFLP markers. 
All isolates of $V$. albo-atrum obtained from the lethal form of hop wilt induced the severe symptoms on the susceptible cultivars Fuggle and Celeia and mild symptoms on the other two inoculated cultivars. The four isolates from the mild form of hop wilt induced mild symptoms on both susceptible cultivars and no symptoms on Wye Target and Cicero cultivars. The characterized isolates differing in terms of pathogenicity were separated into two pathogenicity groups, PG1 and PG2, indicating two different pathotypes of $V$. alboatrum in hop (Table 2).

AFLP analysis. Two isolates each from the mild and lethal forms of $V$. albo-atrum from hop, one from cucumber or petunia, and two isolates of $V$. dahliae, one from hop and one from green pepper, were initially screened with 39 primer combinations. Only intensive and reproducible bands were scored, treating bands with the same mobility as identical fragments. On average, primer pairs produced 17 to 51 bands in a range of 50 to $800 \mathrm{bp}$, giving a total of 1,268 bands. All primer combinations tested clearly distinguished $V$. alboatrum and $V$. dahliae isolates and nine primer combinations showed polymorphisms between mild and lethal isolates of $V$. albo-atrum from hop. Seven primer combinations (Table 3) were chosen for further analysis of 22 isolates; AFLP banding patterns using the EcoRI-TC/MspI-TA primer combination are shown in Figure 1.

Most of the polymorphic bands were detected between $V$. albo-atrum and $V$. dahliae, giving $81.3 \%$ of the AFLP polymorphism. Isolates of $V$. albo-atrum revealed much lower polymorphism, showing differences in only a few polymorphic bands. Polymorphic bands detected among $V$. albo-atrum hop isolates were specific either for mild or lethal isolates. The dendrogram (Fig. 2) produced from the genetic similarity data using the UPGMA method separated isolates of $V$. albo-atrum and $V$. dahliae into two well-defined clusters. Within the $V$. dahliae cluster, hop and green pepper isolates showed some degree of variability, indicating their genetic differences. The isolates of $V$. albo-atrum clustered into two groups, designated as A1 and A2 AFLP groups. Group A2 contained isolates causing the lethal form of hop wilt and group A1 contained mild-form hop isolates and isolates from cucumber and petunia. In both groups, minor genetic variations were detected among isolates, but the clear clustering of $V$. albo-atrum hop isolates into two groups according to their pathogenicity demonstrates two hop $V$. albo-atrum pathotypes. The DNA polymorphisms detected by the AFLP assay were consistent in twice-repeated experiments.

\section{DISCUSSION}

Hop wilt, particularly in its lethal form, is one of the most important diseases in hop. To date, the lethal form of hop wilt has been detected only in England and, recently, in Slovenia, while only the mild form of the disease has been observed in most other hop-growing regions. Patho-

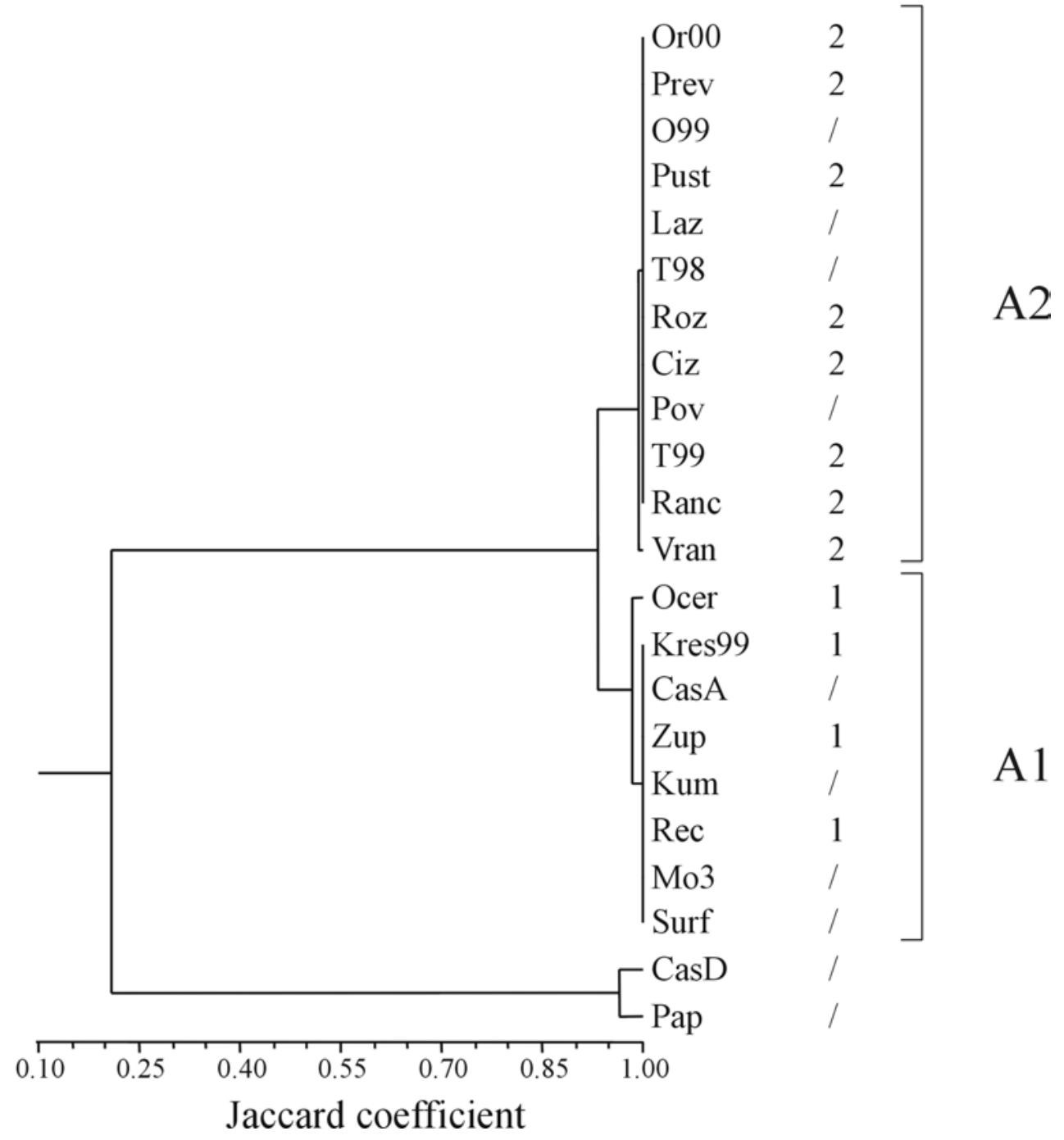

Fig. 2. Dendrogram generated from amplified fragment length polymorphism (AFLP) data of 20 Verticillium albo-atrum isolates and 2 V. dahliae isolates. PG is pathogenicity grouping based on pathogenicity tests. A1 and A2 are pathotype-associated AFLP groups. 
genicity studies of $V$. albo-atrum hop isolates in England have shown variations in pathogenicity, resulting in the identification of four different pathotypes. They have been classified as $F$ (fluctuating) strain, inducing disease of a mild nature in most susceptible hop cultivars; and as PV1, PV2, and PV3 (progressive strains), which cause severe wilt in cultivars with different degrees of resistance $(4,29)$. In our pathogenicity test, two Slovene cultivars in addition to two "standard" English hop cultivars were used, one of each being resistant or susceptible to $V$. albo-atrum. Tested isolates were classified either as PG1 or PG2 pathotype, revealing no observed variation within each PG. The absence of variation in pathogenicity among isolates may suggest homogenous populations of PG1 and PG2, but the data should be extended by testing an increased number of isolates and a wider set of differential hop cultivars. Our AFLP analysis of hop isolates also divided them according to pathogenicity into two well defined groups (Fig. 2). Earlier molecular analysis of $V$. alboatrum from hop, using RFLP (1) and ITS sequences (18), found very little variation among hop isolates. Griffen et al. (9) analyzed $V$. albo-atrum isolates from different hosts, including 35 hop isolates, using RFLPs of rDNA, polymorphism of mtDNA, and amplified polymorphic DNA (APD). High APD polymorphism was detected among hop isolates, but no correlation was found with the pathogenicity $(\mathrm{F}$, PV1, PV2, or PV3), origin, hop cultivar, or year of isolation.

In our study, 20 isolates of V. alboatrum, 18 from hop and 1 each from cucumber and petunia formed two AFLP groups (A1 and A2). Group A1 contained hop isolates classified as PG1 and isolates from cucumber and petunia. One of the PG1 field isolates revealed minor variation (Fig. 2) and some variation was detected between hop and other host isolates (results not shown), suggesting further differentiation within group A1. All hop isolates showing severe symptoms in the pathogenicity test, PG2 pathotype, clustered into AFLP group A2, together with three isolates not tested for pathogenicity. These three isolates were obtained from hop plants with the lethal form of wilt and they revealed the same banding patterns by AFLP as all but one of the isolates in the A2 group; therefore, they are considered to be the PG2 pathotype. In addition to $V$. albo-atrum, isolates of $V$. dahliae were included in the AFLP analysis. Isolates of both species are well separated into two clusters (Fig. 2) with a genetic similarity value of 0.21 . This indicates a substantial genetic difference between the two species. Only two isolates of $V$. dahliae were included in our analysis, but differences were detected between the isolates from different hosts, as reported in other studies $(2,15,20)$. Molecular analyses correspond- ing to pathogenicity studies of fungal pathogens have been found useful, because they provide more data on genetic variability, population structure, and the evolutionary history of the isolates than do pathogenicity tests alone. Studies of Verticillium spp. using different molecular techniques have shown high genetic diversity among species, as well as variation within species, indicating pathotype specialization $(1,15$, 18,19,31). $\quad V$. albo-atrum isolates from different hosts, including hop, have been divided into two groups, L and NL, by means of RFLPs and ITS sequences $(1,3,18)$, whereas $V$. dahliae isolates have been shown to be more host specific $(2,20)$.

In this study, we identified two different pathotypes of $V$. albo-atrum in hop by AFLP analysis. AFLP polymorphisms revealed sufficiently high genetic differences among $V$. albo-atrum hop isolates to differentiate them into two groups that correlate with their pathogenicity. AFLP analysis can generate a large number of fragments sampled from different genome positions, which facilitates finding associations between host or race specificity and pathogenicity. The AFLP technique has been shown to be a very powerful method for genetic diversity studies, because it detects many polymorphisms in a single assay, shows reasonable coverage of the genome, and is highly repeatable. The applicability of AFLP in fungal studies already has been proven $(6,8,17,21,23)$; however, to date, it has not been applied for the analysis of Verticillium spp. In our case, methodological optimization was needed to obtain repeatable and reliable results, in which the appropriate choice of restriction enzymes was particularly important (26).

In conclusion, we report on the determination of two hop pathotypes of $V$. alboatrum found recently in Slovenian hopgrowing regions by means of classical and molecular characterization. However, further investigations are needed, particularly comparison with hop isolates from other countries, to obtain more data on genetic variability, population structure, and origin of isolates.

\section{ACKNOWLEDGMENTS}

We thank M. Dolinar for advice and help in the pathogenicity tests.

\section{LITERATURE CITED}

1. Carder, J. H., and Barbara, D. J. 1991. Molecular variation and restriction fragment length polymorphisms (RFLPs) within and between six species of Verticillium. Mycol. Res. 8:935-94

2. Carder, J. H., and Barbara, D. J. 1994. Molecular variation within some Japanese isolates of Verticillium dahliae. Plant Pathol. 43:947-950.

3. Carder, J. H., and Barbara, D. J. 1999. Taxonomic status of putative Verticillium alboatrum isolates. FEMS Microbiol. Lett. 170:211-219.

4. Clarkson, J. M., and Heale, J. B. 1985. Patho- genicity and colonization studies on wild-type and auxotrophic isolates of Verticillium alboatrum from hop. Plant Pathol. 34:119-128.

5. Dolinar, M. 1975. Hop wilt (Verticillium alboatrum in Verticillium dahliae). Report for 1975. Žalec, Inštitut za hmeljarstvo in pivovarstvo, Žalec, Slovenia.

6. Dunkle, L. D., and Levy, M. 2000. Genetic relatedness of African and United States populations of Cercospora zeae-maydis. Phytopathology 90:486-490.

7. Echt, C. S., May-Marquardt, P., Hseih, M., and Zahorchak, R. 1996. Characterization of microsatellite markers in eastern white pine. Genome 39:1102-1108.

8. Gonzallez, M., Rodriguez, R., Zavala, M. E., Jacobo, J. L., Hernandez, F., Acosta, J., Martinez, O., and Simpson J. 1998. Characterization of Mexican isolates of Colletotrichum lindemuthianum by using differential cultivars and molecular markers. Phytopathology 88:292-299.

9. Griffen, A. M., Bainbridge, B. W., and Heale, J. B. 1997. Ribosomal, mitochondrial and amplified DNA polymorphisms in Verticillium albo-atrum pathogenic to hops, lucerne and other plants. Mycol. Res. 101:1085-1091.

10. Harris, R. V. 1927. A wilt disease of hops. East Malling Res. Stn. Annu. Rep. 1925, Suppl. II:92-93.

11. Heale, J. B. 2000. Diversification and speciation in Verticillium - an overview. In: Advances in Verticillium Research and Disease Management. E. C. Tjamos, R. C. Rowe, J. B. Heale, and D. R. Fravel, eds. American Phytopathological Society Press, St. Paul, MN.

12. Isaac, I., and Keyworth, W. G. 1948. Verticillium wilt of the hop (Humulus lupulus). A study of the pathogenicity of isolates from fluctuating and from progressive outbreaks. Ann. Appl. Biol. 35:243-249.

13. Jakše, J., Kindlhofer, K., and Javornik, B. 2001. Assessment of genetic variation and differentiation of hop genotypes by microsatellite and AFLP markers. Genome 44:773782 .

14. Keyworth, W. G. 1942. Verticillium wilt of the hop (Humulus lupulus). Ann. Appl. Biol. 29:346-357.

15. Koike, M., and Fujita, M. 1996. Random amplified polymorphic DNA analysis of Japanese isolates of Verticillium dahliae and Verticillium albo-atrum. Plant Dis. 11:1224-1227.

16. Lee, S. B., and Taylor, J. W. 1990. Isolation of DNA from fungal mycelia and single spores. In: PCR Protocols. A Guide to Methods and Applications. M. A. Innis, D. H. Gelfand, D H. Sninsky, and J. J. White, eds. Academic Press, San Diego, CA.

17. Majer, D., Mithen, R., Lewis, G. B., Vos, P. and Oliver, P. R. 1996. The use of AFLP fingerprinting for the detection of genetic variation in fungi. Mycol. Res. 100:1107-1111.

18. Morton, A., Carder, J. H., and Barbara, D. J. 1995. Sequences of the internal transcribed spacers of the ribosomal RNA genes and relationships between isolates of Verticillium albo-atrum and $V$. dahliae. Plant Pathol. 44:183-190.

19. Nazar, R. N., Hu, X., Schmidt, J., Culham, D., and Robb, J. 1991. Potential use of PCR-amplified detection and differentiation of Verticillium wilt pathogens. Mol. Plant Pathol. 39:1-11.

20. Okoli, C. A. N., Carder, J. H., and Barbara, D. J., 1994. Restriction fragment length polymorphisms (RFLP) and the relationships of some host-adapted isolates of Verticillium dahliae. Plant Pathol. 43:33-40.

21. O'Neill, N. R., Berkum, P., Lin, J., Kuo, J., Ude, G. N., Kenworthy, W., and Saunders, J. A. 1997. Application of amplified restriction fragment length polymorphism for genetic 
characterization of Colletotrichum Pathogens of alfalfa. Phytopathology 87:745-750.

22. Paplomatas, E. J., and Lampropoulus, C. J. 2000. Molecular characterization of Verticillium spp. by random amplified polymorphic DNA analysis. In: Advances in Verticillium, Research and Disease Management. E. C. Tjamos, R. C. Rowe, J. B. Heale, and D. R. Fravel, eds. American Phytopathological Society Press, St. Paul, MN.

23. Pongam, P., Osborn, T. C., and Williams, P. H. 1999. Assessment of genetic variation among Leptosphaeria maculans isolates using pathogenicity data and AFLP analysis. Plant Dis. 83:149-154.

24. Püntener, W., ed. 1981. Manual for Field Trials in Plant Protection. 2nd ed. Documenta Ciba-Geigy Agricultural Division. Basle,
Switzerland.

25. Radišek, S., Dolinar, M., Simončič, A., and olnir, M. 2001. The state and the activities performed to control hop wilt (Verticillium alboatrum Reinke \& Berthold in Verticillium dahliae Klebahn) in Slovenia in the year 2000. Hop Bull. 8:43-46.

26. Radišek, S., Jakše, J., and Javornik, B. 2001. Optimisation of amplified fragment length polymorphism (AFLP) analysis of hop wilt (Verticillium alboatrum and Verticillium dahliae). Biotechnical Faculty, University of Ljubljana, Res. Rep. (Agric.)77-2:139-146.

27. Rohlf, J. F. 1998. NTSYS: Numerical taxonomy and multivariate analysis system, version 2.02. Exeter Software, Setauket, NY.

28. Sewell, G. W. F., and Wilson, J. F. 1974. Hop wilt, soil temperature and nitrogen. East Mal- ling Res. Stn. Annu. Rep. 1973:203-204.

29. Sewell, G. W. F., and Wilson, J. F. 1984. The nature and distribution of Verticillium alboatrum strains highly pathogenic to the hop. Plant Pathol. 33:39-51.

30. Talboys, P. W. 1972. Resistance to vascular wilt fungi. Proc. R. Soc. (Lond.) 181:319 333.

31. Typas, M. A., Griffen, A. M., Bainbridge, B W., and Heale, J., B., 1992. Restriction fragment length polymorphisms in mitochondria DNA and ribosomal RNA gene complexes as an aid to the characterization of species and sub-species populations in the genus Verticillium. FEMS Microbiol. Lett. 95:157-162.

32. Weising, K., Nybom, H., Wolff, K., and Meyer, W. 1995. Fingerprinting in Plants and Fungi. CRC Press, Inc., London. 